\title{
Contexto científico da pesquisa sobre a edição escolar local, nacional e mundial
}

\author{
Alain Choppin ${ }^{\dagger}$ \\ Tradução e Apresentação: Circe Fernandes Bittencourt \\ 10rcid: 0000-0002-7896-2539
}

\section{Resumo}

A partir dos anos de 1980, a pesquisa histórica sobre livros e edições escolares teve um grande desenvolvimento em numerosos países. Abordamos, primeiramente, as causas principais deste interesse antes de focalizar as principais evoluções deste domínio de pesquisa realizadas nas últimas décadas. 0 enfoque central da exposição é sobre a definição (ou redefinição) do conceito, sobre as extensões deste domínio de pesquisa, sobre o acesso às fontes e sobre a renovação das problemáticas e métodos em um contexto científico cada vez mais marcado por uma dialética entre o local, o nacional e o mundial.

\section{Palavras-chave}

História do livro didático - Edições escolares - Balanço de pesquisas sobre livro didáticoMétodos de pesquisa.

\section{Scientific context of research on local, national and world school editions}

\section{Abstract}

This text addresses a historical research on books and school editions that has developed greatly since the 1980 in many countries. Our approach first addresses the causes of this interest before focusing the main developments in this field of research carried out in recent decades. The central focus of the exhibition is on the definition (or redefinition) of the concept, on the extensions of this research domain, on access to sources and on the renewal of problems and methods in an scientific context increasingly marked by a dialectic between the local, the national and the world.

\section{Keywords}

History of the textbook - School editions - Balance of research on textbooks - Research methods.

1 - Universidade de São Paulo, Faculdade de Educação. São Paulo, SP. Brasil. 


\section{Apresentação}

Esta é uma tradução da conferência Contexte scientifique de la recherche sur l'édition scolaire au plan local, national e mondial, apresentada no dia 5 de novembro de 2007, pelo Prof. Dr. Alain Choppin, na Abertura do Simpósio Internacional Livro Didático: Educação e História, no auditório da Faculdade de Educação de São Paulo (CHOPPIN, 2007). Trata-se de uma publicação inédita deste texto, uma importante reflexão e precioso balanço de pesquisas sobre livros didáticos em escala internacional, uma tarefa à qual este pesquisador vinha se dedicando nos últimos anos de sua vida no Service d'Histoire de l'Éducation de l'Institut National de Recherche Pédagogique - INRP - da França. Esta tradução corresponde a um compromisso assumido com este importante intelectual com quem tive o privilégio de trabalhar e com quem continuamos a aprender pelos seus inúmeros artigos e livros. Este legado de Choppin permanece como uma referência ímpar para os que se dedicam à pesquisa sobre livros didáticos e sobre o lugar que esta literatura ocupa na história da educação mundial.

O Simpósio realizado na FEUSP, em 2007, contou com a participação de pesquisadores de história do livro didático brasileiros e de vários países - França, Itália, Portugal, Espanha, Canadá, Argentina -, além da presença de representantes do MEC, de editoras, pela ABRALE, e de autores de livros didáticos, pela ABRELIVROS. Foram apresentadas por especialistas nacionais e internacionais 176 comunicações, sob diversas abordagens, que levaram Alain Choppin a considerar o encontro de 2007 como representativo da "maturidade da pesquisa histórica sobre o livro e a edição escolar", assim como um marco importante para este campo de investigação, cuja característica tem sido o constante diálogo internacional. Tal característica ainda permanece e torna-se cada vez mais necessária, ao considerarmos dois dos aspectos centrais da obra didática: como expressão de um vasto conhecimento escrito disponibilizado para o conjunto da sociedade, e como mercadoria cultural disseminada em escala internacional. As pesquisas sobre a história do livro didático vinculavam-se, ou, podemos afirmar, ainda vinculam-se, ao futuro desse produto educacional, uma preocupação de Choppin e de muitos estudiosos do livro escolar que mantêm suas investigações alinhadas ao esforço em preservar este material juntamente com um conjunto de documentos a ele articulados.

A presença de Alain Choppin neste evento de 2007 foi decorrente de parte de suas atividades como pesquisador junto ao Projeto Temático da FAPESP Educação e Memória: organização de acervos de livros didáticos, desenvolvido entre 2003 a 2007 na FEUSP. 0 desenvolvimento deste projeto consolidou o Banco de Dados LIVRES (Livros Escolares brasileiros). A constituição do Banco de Dados teve início em 1994, com objetivo de disponibilizar uma coleção de livros escolares produzidos ou que circularam no Brasil desde o século XIX aos dias atuais, com apoio da rede EMMANUELLE, criada por Alain Choppin junto ao INRP. Este projeto inicial foi elaborado juntamente com a constituição de um acervo especial - a Biblioteca do Livro Didático (BLD) -, integrando-se à Biblioteca da FEUSP, e se constituiu, desde sua origem, sob conceitos e categorias próprias da produção didática. Estes têm sido determinantes para a classificação dos gêneros didáticos e formas específicas de disponibilização para pesquisadores. A partir de 2003, as coleções reunidas na BLD integraram o Banco de Dados LIVRES, acrescidas de obras de outras bibliotecas, 
com um acervo de todas disciplinas escolares e de todos níveis de ensino, a partir de 1810, elementar (primário), secundário, técnico, de escolas diferenciadas, destacando-se as de Educação de Jovens e Adultos (EJA) e de escolas indígenas.

A constituição do LIVRES caracterizou-se pelo apoio de pesquisadores especializados em suas diferentes áreas disciplinares e níveis de ensino e inclui obras de diversos acervos, incluindo as das bibliotecas Paulo Bourroul e Macedo Soares (FEUSP), e de outras bibliotecas da USP, assim como de bibliotecas escolares, como a do Colégio Pedro II (NUDOM, RJ), além da Biblioteca Nacional do Rio de Janeiro, a Bibliothèque National de France, dentre outras. Desta forma, LIVRES e BLD foram constituídos por intermédio de pesquisas vinculadas à história dos currículos e disciplinas escolares, história das práticas de leitura e métodos de ensino, e história da formação de professores secundários e primários, e contou com a participação de pesquisadores de diferentes áreas com seus alunos de Iniciação Científica, Mestrado, Doutorado e de Pós-doutorado, de cursos da USP, PUC-SP, Unicamp, Unesp, UFMG, PUC Minas e de outras instituições do Brasil. Neste sentido, o Banco de Dados LIVRES representa um dos principais suportes para investigações sobre obras escolares no Brasil e sua importância reside igualmente em acompanhar as pesquisas sobre a história dos livros e edições escolares.

0 apoio de Alain Choppin foi constante neste percurso, tanto para a construção e atualização do Banco de Dados, como para a integração de sites de diversos países para manutenção de uma rede permanente, em escala nacional e internacional, para o necessário diálogo, conforme esclarece em publicação com o historiador canadense Paul Aubin (AUBIN; CHOPPIN, 2007). Esse ideário permanece por intermédio de um diálogo constante entre o LIVRES e inúmeros outros Bancos de Dados internacionais, iniciado pelo EMMANUELLE, e atualmente em desenvolvimento também junto ao MANES (Espanha), EDISCO (Italia), GLOTREC (GEI - Alemanha), MHEDAR (Argentina).

$\mathrm{Na}$ atualidade, as pesquisas junto ao LIVRES e à BLD integram as atividades do projeto temático Saberes e Práticas em Fronteiras: por uma história transnacional da Educação (1810 -....), financiado pela Fapesp e em desenvolvimento a partir de 2019 sob a coordenação das Professoras Doutoras. Diana Vidal e Carlota Boto, e a participação de numerosos pesquisadores da história da educação de diferentes instituições nacionais e internacionais. Dentre os projetos específicos, o eixo de pesquisa intitulado Arquivos digitais e bibliotecas: história do livro e da leitura tem por objetivos centrais a reorganização da Biblioteca do Livro Didático (BLD), com digitalização das obras, em continuidade ao Projeto Temático LIVRES, e a ampliação de estudos sobre história de bibliotecas para formação de professores por intermédio da organização e digitalização dos acervos Paulo Bourroul e Macedo Soares da Biblioteca da FEUSP. Desta forma, o armazenamento das obras didáticas na BLD tem como princípio a preservação do livro didático articulada a outros documentos sobre seus leitores e autores, e, nesta perspectiva, preocupa-se em pesquisar e organizar também as demais obras de referência com as quais dialoga, em especial as obras de "formação de professores" de pedagogos, historiadores da educação, sociólogos, filósofos, além de periódicos especializados e também manuais escolares de formação do professorado. Nesse sentido, as bibliotecas Paulo Bourroul e Macedo Soares articulam-se aos estudos da Biblioteca do Livro Didático na busca por avaliar e ampliar 
pesquisas do campo da história da educação e da história das disciplinas escolares e dos currículos. 0 projeto se estende ao propor estudos sobre a circulação desse material em termos nacionais e transnacionais em diferentes períodos, o que indicaria a abrangência e a permanência de projetos educacionais sob nova escala.

Tais perspectivas de pesquisas explicitam a importância em divulgar este texto de Alain Choppin assim como a trajetória das investigações dessa área e suas expectativas expressas na palestra proferida em 2007, que, sobretudo, sintetiza sua própria vida de pesquisador, cuja obra constitui um legado e um estímulo para nosso trabalho junto aos atuais desafios da história educacional que têm exigido projetos abrangentes para situar dialeticamente a educação brasileira em diferentes escalas de tempo e de espaços.

Este texto de Alain Choppin é uma reflexão fundamental sobre o significado da maturidade de pesquisas científicas na área e sobre seu dinamismo em uma escala internacional, também decorrente dos avanços da história do livro; além disso, traz uma contribuição fundamental sobre as "incertezas do futuro do impresso e, mais particularmente, sobre o papel que desempenharão, no futuro, os livros junto às novas tecnologias educativas”.

\section{Abertura do Colóquio de São Paulo}

\section{Contexto científico da pesquisa sobre a edição escolar local, nacional e mundial}

É uma grande alegria e uma grande honra estar com vocês no Brasil para a abertura deste encontro científico e participar de suas atividades. 0 programa do evento é rico e estimulante e me fez considerar este Colóquio como o da maturidade da pesquisa histórica sobre o livro e a edição escolar. Inicialmente, gostaria de explicar esta minha avaliação, evidentemente, muito particular.

Tive a curiosidade, o que para os historiadores é um constante e velho hábito, de fazer um levantamento sobre programas de colóquios dos anos de 1980 e da década seguinte, em que historiadores apresentavam os manuais escolares: em tais encontros, seminários ou jornadas de estudos, os livros didáticos não ocupavam um lugar central e eram apresentados, de forma predominante, como fonte de pesquisa, ou integravam estudos temáticos em uma perspectiva, na maior parte das vezes, ideológica ou sociológica, mas raramente epistemológica; o método dominante recaia, quase exclusivamente, sobre análises dos conteúdos dos manuais. 0 ano 2000 me parece ter sido o ano da virada, com a organização em Sherbrooke, na cidade de Quebec, no Canadá, do primeiro Congresso Internacional sobre a história da edição em escala mundial, congresso em que a história da edição escolar, situada, até então, de forma quase invisível, tornou-se, pela primeira vez, objeto específico de uma comunicação em nível internacional. No ano seguinte (2001), ocorreu um colóquio que podemos qualificar, de certa forma, como fundador da temática: foi organizado pelo ISCHE, International Standing Conference of History of Education, em Alcalá de Henares, na Espanha, e este encontro foi consagrado especificamente ao livro e à educação. Na primavera de 2006, ocorreu em Montreal um outro importante colóquio 
internacional intitulado "O livro escolar daqui e de outros lugares, o de ontem e do amanhã”, que reuniu pesquisadores de aproximadamente vinte países de diversos campos disciplinares: historiadores, mas também sociólogos, linguistas, pedagogos, museólogos, cientistas entre outros estudiosos para confrontar seus olhares sobre um objeto de pesquisa comum, o livro didático. 0 peso da história ficou evidente, uma vez que mais da metade das comunicações inscritas apresentou uma perspectiva diacrônica sobre este material. E hoje, em São Paulo, no Brasil, se encontram pesquisadores, professores, autores, editores e profissionais da educação em um evento que não se dedica a uma temática isolada, mas se realiza sob uma perspectiva globalizante, em que são abordadas problemáticas essenciais da pesquisa sobre livros didáticos.

Inicialmente quero destacar o crescimento da pesquisa histórica sobre os livros didáticos, mas acrescento que também se deve fazer sempre referência aos trabalhos que foram e ainda estão sendo realizados por historiadores sobre a produção didática contemporânea.

A atenção centrada em manuais utilizados - ou suscetíveis de serem utilizados ficou por muito tempo limitada a análises de seu conteúdo intelectual. A partir do final do século XVIII na Europa, e logo a seguir em outros continentes, a educação se desenvolveu sob o poder do Estado e este exerceu uma política extremamente vigilante na maioria dos países. Embora tenha havido algumas exceções, como na Inglaterra, os poderes públicos passaram a definir os conteúdos que os alunos deveriam aprender e os professores ensinar, e, na maior parte das vezes, as obras eram submetidas aos programas oficiais de forma explícita e minuciosa.

Os livros didáticos, por serem considerados como poderosos instrumentos na constituição identitária dos Estados Modernos, adquiriram, a partir desse período, uma dimensão estritamente nacional e foram tomadas medidas constantes pelo poder público para assegurar o controle deste material: na Polônia, a partir de 1777; na França, em 1793; na Espanha, desde 1813 (KUHN, 1977). Alguns países detiveram também o monopólio da produção e difusão das obras escolares, mas a maioria adotou procedimentos, muitos ainda em vigor, para avaliar as obras escolares do setor privado, com autorizações para usos em salas de aula, para fazer modificações, ou para descartá-los definitivamente. Embora a avaliação da produção escolar seja exercida pelo poder político ou por autoridades religiosas, ou pelos dois, em uma relação conflituosa ou não, ou mesmo quando as decisões sejam tomadas pelo poder local, este controle caracteriza-se como uma medida conservadora mesmo quando obedece a critérios científicos, técnicos, pedagógicos ou financeiros, que podem desempenhar, por princípio, um papel positivo, mas por se constituir, essencialmente, como estratégia para assegurar uma conformidade quanto ao conteúdo ideológico, político, moral ou religioso das obras em relação aos objetivos do poder vigente.

A avaliação propriamente didática e pedagógica dos manuais é um fenômeno mais recente: os poderes públicos tendem a preocupar-se mais com os conteúdos e pouco se referem aos métodos, e, quando abordam este aspecto, o processo de seleção das obras escolares, assim como as análises desenvolvidas com objetivos de aperfeiçoar a metodologia, ficam sempre submetidos a interesses econômicos ou políticos. Os historiadores que analisaram as atividades das comissões encarregadas de examinar e "classificar" os manuais (penso especialmente nas atividades avaliativas da França, Itália 
ou Grécia) destacaram a influência de determinados editores nas avaliações, e como tais editoras, muitas vezes beneficiando-se da conivência administrativa, conseguiram obter vantagens econômicas significativas neste processo. Nos países soviéticos, como a ex-URSS, as edições oficiais Prosweschtschenie, de Moscou, e as da Universidade de Tartu, na atual Estônia ${ }^{2}$, ou as produzidas na ex-Alemanha Leste, de acordo com as investigações realizadas pelo Wolfgang-Ratke Institut de Halie-Kothen ${ }^{3}$, o poder político soviético encomendou e financiou uma série de pesquisas para a confecção de livros mais "eficazes", isto é, de obras mais adaptadas para a difusão da mensagem ideológica então em vigor (JEISMAN, 1987).

Os conteúdos dos livros escolares tornaram-se, igualmente, o tema preferencial das inúmeras iniciativas internacionais que ocorreram ao longo do século $\mathrm{XX}$ com objetivo de denunciar e tentar eliminar os preconceitos nacionais ou os estereótipos suscetíveis de despertar, de manter ou reativar os sentimentos de hostilidade entre os povos. 0 primeiro Congresso Mundial para a Paz, que ocorreu em Paris em 1889, apresentou a literatura escolar de forma bastante crítica, como fonte de desentendimentos entre as nações e recomendou, especialmente aos autores e aos editores, limitar o lugar reservado à história militar. Mas esta ação teve poucos e modestos resultados.

Este movimento, interrompido pela Primeira Guerra Mundial, foi retomado após o fim das hostilidades e se internacionalizou no decorrer do período "entre guerras". Uma vasta campanha de revisão dos livros escolares foi realizada entre 1919 e 1933, por organizações governamentais e também privadas, tanto nacionais como internacionais. A campanha visava essencialmente os livros de história e, em menor escala, as antologias e livros de leitura, de instrução cívica e de geografia. A iniciativa mais marcante foi, sem dúvida, a ampla enquete lançada em 1921 por uma organização internacional privada, a Fundação Carnegie para a Paz Internacional, com a finalidade de pesquisar em antigos livros dos países beligerantes as tendências relacionadas a possibilidades de uma conciliação internacional ${ }^{4}$. No mesmo ano, a Sociedade das Nações solicitou à Comissão Internacional de Cooperação Intelectual (C.I.C.I.), uma reunião de personalidades de prestígio, como Henri Bergson, Marie Curie e Albert Einstein, com objetivo de ampliar os esforços para esta tarefa. Em 1924, foi adotado um programa internacional de revisão de livros didáticos que resultou na redação das Resolutions Casarès, nome do representante da Espanha e autor da proposta publicada em 1926.

A ascensão ao poder do nacional-socialismo na Alemanha, em 1933, interrompeu o movimento de cooperação que havia realizado um trabalho significativo nos anos que precederam a $2^{\text {a }}$ Guerra Mundial e por intermédio do qual haviam sido estabelecidos acordos bilaterais, notadamente na Europa e no continente americano. Paralisados durante

2- 0 documento principal sobre este tema foi produzido a partir de encontros realizados pela Universidade de Tartu, Estônia: Problems of Textbook Effectivity: Papers on Education II, In: Acta et Commentationes Universitatis Tartuensis, 926, 1991.

3- Os procedimentos de inculcação ideológica do texto escolar foram evidenciados pela análise de uma obra, publicada em 1987 e muito utilizada durante muitos anos na ex-Alemanha, por Karll-Ernest Jeismann, (1987). Os trabalhos avaliativos dos livros se desenvolveram em uma perspectiva mais "democrática após a queda do Muro de Berlim", conforme publicação de BAUMANN, Manfred. Wissenschaftliches zentrum fur schulbuchforschung am Wolfgang-Ratke-Institut Kothen Kriterien Zurauswahl von Shulbuchern. Kothen: Padagogiscwe Hochschule Halle-Kothen, 1990.

4 - A pesquisa se fez com a produção de cinquenta países. Os resultados foram publicados alguns anos depois, em 1926, e revisados em 1932. Ver: (PRUDHOMMEAUX, 1926). 
mais de dez anos pela chegada do totalitarismo e pelo conflito mundial, os trabalhos foram retomados apenas ao final das hostilidades, sob o patrocínio da UNESCO, e, alguns anos mais tarde, pelo Conselho da Europa, observando-se também iniciativas de associações de historiadores 5 .

As pesquisas internacionais dedicadas aos manuais escolares (quase que exclusivamente sobre seus conteúdos), assim como as regulamentações sobre as produções escolares de cada país, eram bastante semelhantes e, por serem estudos bilaterais, a tendência que se manteve foi o confronto entre suas produções nacionais.

Numerosas instituições científicas, algumas mais ou menos próximas ao poder político, outras totalmente independentes, dedicaram-se à melhoria dos livros ${ }^{6}$. Dentre as instituições, destacou-se o Institut Georg Eckert com uma importante contribuição para elevar as exigências científicas da pesquisa, notadamente a partir de meados dos anos de 1970, com uma expansão significativa de investigações e pela introdução de novas problemáticas e métodos.

Em 1966, Otto-Ernest Schuddekopf fez as primeiras críticas sobre as pesquisas dos livros escolares ao afirmar que "não existe método nem didática para o trabalho com os livros didáticos: é uma arte pragmática que se desenvolve a partir de 1918 e sobretudo a partir de 1945." (Schuddekopf, 1966, p.42). Alguns anos mais tarde, a baixa qualidade de numerosos trabalhos científicos foi denunciada por Horst Schallenberger (1976), fundador, com Gend Stein, do instituto de pesquisa sobre os livros escolares de Duisburg:

Normalmente as premissas científicas e os fundamentos metodológicos de numerosas pesquisas realizadas sobre os livros escolares não são objetivas e, muitas vezes, caracterizam-se por uma total ausência de reflexão. (SCHALLENBERGER, 1976, p. 4).

No decorrer dos anos de 1970 houve uma mudança determinante em relação à concepção de pesquisa sobre os manuais escolares. Em um artigo publicado em 1987, Karl-Ernest Jeismann identificou dois períodos sobre as pesquisas. 0 período clássico da revisão internacional dos manuais escolares foi caracterizado por um conhecimento incompleto de seu objeto, pela ausência de questionamentos sobre a eficiência do livro, e pela referência sempre constante e limitada à produção nacional (Jeismann,1987). 0 autor destaca que neste período, entre final dos anos de 1970 e início dos anos de 1980, estava havendo mudanças no contexto escolar em numerosos países, e estas foram determinantes para a desarticulação entre os conteúdos de ensino propostos e as aquisições reais pelos alunos. A pesquisa não poderia, então, limitar-se unicamente ao livro escolar: ela deveria preocupar-se com outros meios de ensino complementares, especialmente os materiais que concorriam com ele ou, mesmo no caso, em que novos meios de comunicação estavam

\footnotetext{
5 - Dispomos de abundante literatura sobre o histórico das iniciativas internacionais realizadas com o objetivo de revisar os manuais escolares. Além dos títulos já mencionados anteriormente, podemos citar ainda: Eckert, Georg (1960); Dance, Edward Herbert (1960); Schuddekopf, OttoErnest (1966); Vigander, Haakon (1967); Jeisman, Karl-Ernest (1979); Riemenschneider, Rainer (1981); Mehlinger, Howard D. (1985); Luntinen, Pertti (1989).

6 - Podem-se encontrar informações pormenorizadas sobre os principais lugares que realizaram pesquisas no trabalho de Johnsen Egil Børre, de 1993, p. 65-108.
} 
substituindo totalmente o livro. A coexistência no ambiente escolar de informações provenientes de outros meios de comunicação tendia a eliminar, definitivamente, as "fronteiras fechadas" da escola e fazia com que a avaliação sobre os manuais escolares pudesse ser aprimorada. Tornou-se mais importante examinar a formulação dos objetivos e de estratégias para atingi-los do que analisar apenas, e de forma isolada, os conteúdos do ensino. Este foi particularmente o caso de países em que o manual não fornecia mais aos alunos os pré-julgamentos do autor, mas lhes permitia a possibilidade de construir uma opinião pessoal por meio de discussões onde se confrontam análises e opiniões diversas:

A revisão internacional dos livros escolares deveria portanto dedicar-se ainda mais e o mais rápido possível ao exame dos objetivos e dos procedimentos de ensino [...]. A análise dos manuais escolares passou de uma avaliação puramente metódica de correção de conteúdos ou sobre a pertinência de suas afirmações categóricas para uma área de pesquisas complexas. (JEISMANN, 1987, p. 11).

Esta mutação do conceito de Schulbuchrevision (avaliação dos livros didáticos) ao de Schulbuchforschung (pesquisa sobre manuais escolares) suscitou, no decorrer de 1970 e anos seguintes, uma abundante literatura de pesquisadores na Alemanha (Duisburg e Braunschweig) e em outros países, especialmente nos Estados Unidos e na Suécia, com destaque ao trabalho de Egil Borre Johnsen (1993). E, de acordo com Fritsche (1992), as pesquisas sobre os manuais estavam, na década de 1990, dedicando-se aos métodos, à definição do campo de investigação e às suas problemáticas. Desta forma, tornouse evidente que a "Pesquisa sobre manuais escolares" (Schulbuchforschung) não é uma disciplina acadêmica e que não são os métodos que determinam sua unidade, mas seu objeto de investigação. Wolfgang Jacobmeyer (1990), neste mesmo período, definiu a pesquisa sobre livro didático como um "amálgama de disciplinas ou trabalho interdisciplinar" com o objetivo de apreender o livro em seu contexto global e que visa, primordialmente, a "recontextualizar seu discurso" (JACOBMEYER, 1990, p. 10).

Peter Weinbrenner (1986), um dos mais importantes teóricos da pesquisa sobre o livro escolar, identificou três grandes categorias sobre o campo: as pesquisas que consideram as diversas etapas que integram a vida do livro; as que se dedicam ao produto propriamente dito; e aquelas que estudam sua recepção. Este autor não se limitou a proceder a um inventário minucioso de tipos de investigação, mas estabeleceu uma classificação racionalizada e hierarquizada sobre elas.

Vejamos a seguir a pesquisa sobre a história do livro e da edição escolar, ou seja, o estudo da produção escolar fora do circuito escolar, de obras que não são mais usadas.

Em outras ocasiões havia apresentado as razões externas pelas quais os livros didáticos antigos ficaram por muito tempo ausentes das preocupações dos historiadores: a banalidade do objeto, sua produção abundante e excessiva, sua difusão massiva e o pouco valor venal, que não suscitou interesse entre conservadores de bibliotecas, nem o entusiasmo catalográfico entre colecionadores ou bibliógrafos; a forma geralmente incompleta das coleções, assim como a raridade ou carência de catálogos de editores ou de repertórios específicos também dificultaram (e ainda dificultam) o trabalho dos 
historiadores em sua tarefa de levantamentos prévios e exaustivos. Desta forma, estas dificuldades tiveram um efeito de dissuasão e desencorajaram os pesquisadores a realizar estudos sistemáticos e abrangentes, além do caráter massivo e a obsolescência rápida de uma produção considerada altamente repetitiva. Entretanto, em meio a esta produção abundante, muitos pesquisadores destacaram algumas obras que se tornaram bastante conhecidas pelo grande público. Foi o caso dos livros de leitura, que muitas vezes foram elevados a um patamar de verdadeiras instituições pela sua numerosa vendagem, e foram considerados como best-sellers pelo impressionante número de reedições ou de reimpressões: na França, Le tour de la France par deux enfants, de G. Bruno, teve 432 edições entre 1877 a 1960, além de inumeráveis traduções e adaptações, como a Viaje a través do México por dos ninos huerfanos, de Lucio Tapia, no México, ou o célebre Através do Brasil, de Manoel Bomfim e Olavo Bilac, no Brasil; os Mac Guffey Eclectic Readers, que venderam nos Estados Unidos 122 milhões de exemplares entre 1826 e 1920; a obra Der Kinderfreund, de Friederich Eberhard von Rochow, publicada em Frankfurt entre 1776 e 1779, considerada como o primeiro manual profano traduzido em toda a Europa; Le Merveilleux Voyage de Nils Holgersson, de Selma Lagerlof na Suécia; Cuore, do italiano Edmondo de Amicis, publicado em 1886 e traduzido em vinte e cinco línguas, que obteve um grande sucesso notadamente na Argentina, sob o título de Corazón, diário de um nino, e no Brasil, com o título de Coração, diário de um menino; a obra Juanito, uma adaptação espanhola de Giannett, do italiano Luigi Alessandro Parravicini; a coleção El Nene de Andrés Ferreyra, na Argentina; e, certamente, as célebres edições de Reinações de Narizinho, de José Bento Monteiro Lobato, publicada no Brasil em 1920.

A partir dos anos de 1960, mas sobretudo nas duas últimas décadas do século $\mathrm{XX}$, as pesquisas dedicadas à história dos manuais escolares tiveram um crescimento considerável. Este dinamismo corresponde, pode-se dizer, ao fenômeno de "colocar o tema na ordem do dia”. Era paradoxal, efetivamente, que a edição escolar continuasse a ser deixada de lado, por tanto tempo, ao se constatar a forte presença dos livros didáticos no mundo inteiro e o peso considerável que representa este setor na economia editorial dos séculos XIX e XX. Sabe-se que é impossível abordar a atividade editorial de um país como o Brasil, apenas como exemplo, sem fazer referência ao setor escolar, pois os livros de ensino correspondem, desde o início do século XX, a mais de dois terços dos livros publicados. Alguns países já possuíam uma certa tradição de estudos históricos antes dos anos de 1980, como os Estados Unidos, a Alemanha, o Japão, o Reino Unido ou mesmo a França. Mas os historiadores que se dedicaram às produções escolares não se interessaram, com exceção dos anglo-saxões, pelas questões editoriais: seu propósito principal era analisar os conteúdos das obras.

Estes trabalhos estavam inseridos em um contexto particular: as sequelas da Segunda Guerra Mundial, a descolonização, a "Guerra Fria”, a democratização dos sistemas educativos e a aceleração sensivel dos progressos tecnológicos que levantavam questões sobre certos valores tradicionais. Durante cerca de vinte anos, o essencial da produção científıca dos historiadores ficou limitado a análises do conteúdo ideológico de sua própria disciplina, ou a estudos da imagem que os antigos manuais de leitura, de instrução cívica, 
ou ainda de geografia ${ }^{7}$, apresentavam sobre a sociedade de sua época. Os títulos das teses utilizavam, na maioria das vezes, a palavra "Representation", "Darstellung" ou "Image", ou ainda apresentavam formulações mais elípticas como "Le monde paysan dans les manuels de lecture du primaire de la Troisième République”. Desta forma, cerca da metade das publicações na França relativas à história do livro e da edição escolar até 1980 era realizada sob uma perspectiva ideológica ou sociológica ${ }^{8}$.

Outra característica das pesquisas foi seu caráter limitado, às vezes reduzidas a simples compilações, com um número de trabalhos bastante medíocres. Constatava-se que um número significativo de pesquisas apresentavam graves déficits metodológicos, análises superficiais e chegavam, muitas vezes, a conclusões discutíveis, e, na maioria das vezes, infundadas. Esta constatação sobre as conclusões simplistas havia sido apresentada por G.H. Harper em 1980, ao analisar a produção científica anglo-saxônica:

[...] efetivamente é desagradável que tenha aparecido nos anos de 1960 um grande número de estudos desnecessários, que não precisavam ser realizados. Sua característica geral é fornecer uma lista cronológica de livros e omitem-se, muitas vezes, os que abordam disciplinas que não são mais ensinadas atualmente nas escolas, e caracterizam-se também por apresentar comentários ingênuos e curiosos; e muitas vezes não apresentam uma bibliografia dos manuais citados. Estes estudos caracterizam-se também por serem mal redigidos, sem releituras, e se apoiam em hipóteses ingênuas sobre o papel disseminador exercido pelo livro para exaltar os líderes e generalizar a civilização do país de origem das obras. (HARPER, 1980, p. 31).

E, de fato, foi apenas no decorrer dos anos de 1970 que alguns historiadores começaram a manifestar maior interesse em relação aos livros didáticos que não eram mais utilizados, também após uma leitura mais atenta de um antigo texto de Hans-Joachim Schoeps (1954) sobre a importância de estudo comparativo de obras didáticas para o estudo da história das mentalidades. Sua sugestão foi acompanhada de uma reflexão sobre os métodos convenientes a serem utilizados para analisá-los. Com base neste autor, foi realizado em 1972 o estudo sobre o ensino de história na Suécia entre 1820 a 1965, pelo historiador Goran, que apresenta num capítulo, o segundo, de forma minuciosa, os princípios e as vantagens do método de análise quantitativa por ele utilizado e faz severas críticas às práticas de pesquisas sobre os livros escolares majoritariamente utilizadas:

[...] a característica do que tem sido considerado como resultado científico é a de que tais resultados devem tornar-se independentes de seus autores e devem servir para outros pesquisadores. E

7- Os trabalhos realizados no Georg-Eckert-Institut (GEI) são quase que exclusivamente, mesmo atualmente, sobre estas disciplinas. A bibliografia publicada em sua revista Internationale Shulbuchforschung apenas identifica as publicações científicas sobre manuais de História, Geografia, Ciências Sociais e livros de leitura.

8- Cf. CHOPPIN, Alain. L'histoire des manuels scolaires: um bilan bibliométrique de la recherche française. In: CHOPPIN, Alain (org.). Manuels scolaires. Etats et sociétés XIX- XX siècles. Histoire de L'Education, n. 58 (spe.), p. 165-185, mai 1993. Este estudo evidenciou também o interesse crescente pelas disciplinas literárias (particularmente as de caráter histórico), e por obras de ensino primário do final do século XIX. Comparando a produção científica francesa das décadas de 1960 e 1970 a dos anos de 1980 a 1993, os estudos ideológicos e sociológicos passaram de $47 / 2 \%$ a $34,7 \%$. 
este não tem sido o caso dos métodos de investigação normalmente utilizados sobre os livros atualmente. (GORAN, 1972, p. 136).

Ao final da década de 1970, esta "tomada de consciência” se manifestou de forma mais evidente com publicações quase simultâneas, em diferentes países, e com contribuições que destacam a importância do livro escolar como fonte para os historiadores da educação, mas também para os próprios historiadores do livro: Hilde Coeckelberghs na Bélgica; Rainer Riemenschneider na Alemanha; G. H. Harper na Grã-Bretanha; Colin Mc George na Nova Zelândia; e eu mesmo, Alain Choppin, na França. É importante destacar que esta nova produção não foi um movimento articulado e pode-se verificar que também em vários outros lugares surgiu uma série de reflexões ou de iniciativas isoladas que, em um determinado momento, passaram a desenvolver, por caminhos diversos, suas pesquisas, e chegavam a conclusões, muitas vezes, similares. Pode-se afirmar que a partir deste período foi quase impossivel retornar às antigas análises e estas caracterizavam-se por atender a várias necessidades: esclarecer os objetivos, definir o objeto da pesquisa, elaborar métodos, preservar os documentos primários e permitir acesso a eles, avaliar a pesquisa em um contexto internacional e considerar os contextos nos quais os livros foram concebidos, publicados, difundidos, consumidos e apreendidos. Esta reflexão metodológica, que está no centro de toda a atividade de pesquisa, tornou-se um princípio vital e proporcionou, há aproximadamente trinta anos, numerosos debates e produziu uma rica literatura que legitima sua qualidade científica.

A dinâmica que caracteriza a pesquisa na atualidade resulta também de uma série de fatores conjunturais: o interesse crescente de historiadores profissionais ou não sobre as questões educacionais, área na qual a demanda social tem se tornado cada vez mais forte; a preocupação de muitas populações em construir ou redescobrir uma identidade cultural que necessita recuperar os acontecimentos históricos mais ou menos recentes; as consequências do colapso soviético, ou, ainda, o recrudescimento de aspirações regionalistas; o desenvolvimento de reivindicações de minorias; os avanços que se realizaram sobre a história do livro em numerosos países e de grandes sínteses, especialmente, sobre a história da edição contemporânea; o progresso considerável de técnicas de armazenamento, de tratamento e de difusão de informações que estavam apenas à espera de uma resposta adequada ao gerenciamento e crescimento de uma quantidade de documentação bastante numerosa de produções escolares; as incertezas sobre o futuro do impresso, e mais particularmente sobre o papel do livro didático no futuro frente às nova tecnologias educativas principalmente nos ambientes digitais.

Mas esta dinâmica possui também causas estruturais: a definição mesmo do objeto livro didático, a multiplicidade de suas funções, a coexistência de outros suportes educativos e a diversidade de sujeitos envolvidos.

Para os contemporâneos, o livro didático é um objeto banal, familiar a ponto de parecer inútil defini-lo, mas para o historiador que constrói seu objeto de pesquisa surge de imediato a necessidade de uma definição, de uma delimitação. Esta é uma questão recorrente na historiografia e suscitou, assim como continua a suscitar, uma abundante literatura e numerosos debates. Um encontro internacional organizado pelo Internationale 
Gesellschaft fur Historiche und Systematische Schulbuchforschung, em Ypres, na Bélgica, tinha como tema Was macht(e) ein Schulbuch zu einem Schulbuch, que podemos traduzir de uma forma mais simples como $O$ que é que faz ou o que se faz com um livro para que ele se torne um livro didático?

Em todos os países, a pluralidade de funções do manual se traduz inicialmente pela sua terminologia: a profusão de expressões que foram ou ainda têm sido utilizadas, assim como a imprecisão e a instabilidade de suas acepções, mostram que os contemporâneos não concebem a literatura didática como um conjunto homogêneo.

Em um artigo que sairá em breve ${ }^{9}$, examinei, de forma sistemática, as palavras ou expressões utilizadas em cerca de trinta línguas para designar os livros didáticos. Esta abordagem terminológica ou léxica é rica de ensinamentos, mesmo considerando que ela apresenta mais perguntas do que respostas: certas expressões remetem ao contexto institucional na qual a obra é utilizada ou para quem é destinada (caso, por exemplo, do alemão Schulbuch, do húngaro Iskolai tankonyvek, ou ainda do chinês Xuê xiao shu); outros destacam sua função didática: o livro escolar é concebido como um livro que serve para ensinar (em português, Livro didático; em árabe, Eddirasat kitab ), ou um livro para aprender (em russo, Uchébnik; em hebraico, Seter Limoud); a terminologia identifica também os conteúdos de ensino, tanto de uma forma indiferenciada, como para livros que apresentam conhecimentos enciclopédicos, tais como os livros de leitura atuais (em grego, Avayvwotikov, ou ainda Avayvwajara; em japonês Kyokasho); ou faz referência à matéria específica da obra (em inglês, grammar; em espanhol, Aritmética; em alemão, Schulgeschichtsbuch); muitas vezes, é comum o inverso, ou seja, é a natureza da aprendizagem que designa o livro escolar: métodos de leitura, alfabetos e abecedários (em inglês, Spellers; em polonês, Elementarz); numerosas expressões levam em conta igualmente o formato do material, seja uma obra de tamanho pequeno, que seguramos em nossas mãos, ou a que está facilmente a seu alcance (em francês, Manuel; em neerlandês, Handboek); outras expressões utilizadas frequentemente são as que remetem ao "texto": trata-se de uma referência à importância do conteúdo (em italiano, Libro di testo; em espanhol, Texto escolar).

Esta análise mostra que o livro didático, sob suas diversas denominações, tornou-se um objeto planetário e identificou também que as denominações locais ou tradicionais permaneceram por longo tempo, e algumas ainda estão em uso, como é o caso, por exemplo, da palavra alemã Fibel (de Bíblia), que designa atualmente todo livro de leitura. A constituição na Europa, e em outros países, de sistemas de ensino com uniformização de conteúdos e de métodos, provocou um fortalecimento da edição escolar, uma normatização de suas produções e, portanto, fez emergir uma nomenclatura específica em que se constata um léxico que remete à complexidade essencial do livro didático. Constata-se assim que, de acordo com os períodos e contextos culturais, muitos vocábulos relativos ao livro escolar testemunham as influências ou trocas culturais que ocorreram nestes espaços.

9- Trata-se do artigo de Alain Choppin, Le manuel scolaire, une fausse évidence historique, publicado em 2008, na Histoire de l'Éducation do INRP, n. 117, e traduzido em pela Revista História da Educação da Associação Sul-riograndense, em 2009 (he.asphe@gmail.com). Disponível em: http://histoire-education.revue.org/565. 
As fronteiras entre o mercado do livro escolar e os de outras produções impressas com as quais eles compartilham tradicionalmente os mesmos objetivos e produzem conteúdos similares ou que visam ao mesmo público, são também incertas e flutuantes. Este é o caso especialmente dos livros religiosos por intermédio dos quais os livros escolares incorporaram a estrutura catequética por "perguntas e respostas", das publicações destinadas ao mercado da educação doméstica, de manuais concebidos para uso no meio comercial e profissional, de obras de vulgarização científica, ou ainda da "literatura infantil e da literatura juvenil". Estas categorias, sem serem exclusivas, se interpenetram ou se sobrepõem com muita frequência. 0 estudo realizado por Marisa Lajolo sobre as produções de José Bento Monteiro Lobato e o futuro editorial da boneca Emília publicada no início dos anos de 1920 é um exemplo, dentre outros, desta permeabilidade entre tais gêneros. 0 conceito de "livro didático" é, assim, recente, sendo estreitamente ligado ao desenvolvimento e à generalização de um mercado institucional, isto é, à organização de sistemas educativos nacionais.

0 dinamismo da pesquisa também decorre da complexidade do livro: os livros escolares possuem, conjuntamente ou não, múltiplas funções: o estudo histórico mostra ser possível reagrupar suas funções em quatro categorias, que podem variar, consideravelmente, de acordo com as áreas sócio culturais e com a política educativa em diferentes períodos: as disciplinas, os níveis de ensino, os métodos e seus diferentes usos:

1- Uma função referencial, curricular ou programática, a partir da existência de programas de ensino: o livro é então uma tradução fiel do programa ou, quando se insere no jogo da livre concorrência, torna-se uma de suas interpretações possíveis; ele constitui o suporte privilegiado dos conteúdos educativos, o depositário de conhecimentos, de técnicas, ou de um saber específico que um determinado grupo social considera necessário transmitir às novas gerações.

2- Uma função instrumental: o livro implementa os métodos de aprendizagem, propõe exercícios ou atividades que, segundo os contextos, visam facilitar a memorização dos conhecimentos, favorecer a aquisição de competências disciplinares ou transversais, a apropriação de determinado saber, de métodos de análise ou de resolução de problemas etc.

3- Uma função ideológica e cultural: é a função mais antiga iniciada a partir do século XIX, com a constituição de Estados-nação e com o desenvolvimento dos principais sistemas educativos; o livro didático se constituiu como um dos vetores essenciais da língua, da cultura e dos valores das classes dominantes.

4- Uma função, enfım, de documento: o manual fornece, sem orientar a leitura, um conjunto de documentos textuais ou iconográficos, cuja observação ou a confrontação são susceptiveis de desenvolver o espírito crítico do aluno; esta é uma função que surgiu apenas recentemente na literatura escolar, e está longe de ser universal.

É importante acrescentar que o livro didático não é o único que participa da educação da juventude, mesmo no interior do ambiente escolar: independentemente da parafernália de materiais que possam desenvolver funções específicas (livro, caderno de exercícios, dicionário etc.), foram sendo criados outros numerosos produtos pedagógicos 
com funções didáticas (quadros de leitura, murais, imagens fixas ou animadas, discos, televisão, filmes...), mas até os anos de 1980, tais instrumentos eram utilizados, geralmente, apenas como complemento do livro e limitavam-se a determinadas atividades. Alguns destes instrumentos são ainda concebidos originariamente como complementares, muitas vezes indissociáveis das produções impressas: muitos livros trazem, com novos formatos, documentos como uma fita cassete ou um CD-Rom, mas estes se apresentam de maneira que não possam ser utilizados de forma independente. Mas é importante assinalar que o livro, na atualidade, tende a participar cada vez menos do mundo do impresso e cada vez mais do conjunto das multimídias. Nesta perspectiva, as normas de descrição catalográfica internacional, muitas vezes, abandonam as das bibliotecas para integrar as do setor mediático.

Em países industrializados, têm surgido numerosos novos produtos tecnológicos, tais como os "manuais digitais", ou ainda plataformas digitais que constituem, na web, novos campos de aprendizagem (os sites pedagógicos das grandes bibliotecas ou de museus, por exemplo), e estes se apresentam como uma das alternativas aos manuais impressos em papel. A pesquisa sobre o livro didático deve (deverá ou deveria), pois, necessariamente, considerar o impacto do que tem sido convencionalmente denominado de revolução tecnológica no campo da edição clássica, porque estes novos instrumentos interferem sobre a concepção, sobre a estrutura, a difusão e usos dos livros didáticos impressos, mas é importante assinalar que o modelo característico do livro tradicional interfere, sem dúvida, de forma inconsciente, na estrutura e na apresentação dos novos instrumentos de ensino e aprendizagem.

Esta diversificação de oferta de materiais educativos não é decorrente apenas das evoluções técnicas: ela expressa uma evolução social e pedagógica.

0 manual escolar integra muitos atores na comunidade nacional: grupos políticos, responsáveis religiosos, profissionais do livro, representantes do corpo de educadores, pais dos alunos, cientistas, associações diversas etc. É por esta condição que as discussões e debates sobre livros didáticos não são tranquilos e são pouco serenos: objeto atualmente bastante generalizado em escala universal, manipulado, lido e comentado, não para de suscitar controvérsias, tanto no interior da opinião pública nacional (ao menos nos países onde existe uma certa liberdade de expressão), quanto em debates internacionais. E todas estas reações e polêmicas fornecem ao historiador uma fonte de pesquisa bastante rica e que necessita ser mais explorada.

Como se constata, a pesquisa histórica sobre o livro e a edição escolar aborda aspectos diversos e esta multiplicidade de abordagens provoca uma diversidade de investigações. A produção científica consiste essencialmente em artigos isolados, publicados muitas vezes em revistas improváveis, o que torna particularmente difícil de identificá-la e localizá-la. No entanto, podemos distinguir três grandes categorias de pesquisa:

- as mais numerosas são as que se dedicam ao conteúdo intelectual do livro: a grande maioria dos estudos é realizada em uma perspectiva sociológica ou ideológica, e mais raramente abordam questões de ordem linguística, científica, ética, didática, semiótica ou epistemológica - esta tem sido a opção mais comum selecionada pela Alemanha e Japão 
a partir da Segunda Guerra mundial, pela França, a partir dos anos de 1960, e, pelo menos em um primeiro momento, pela maior parte dos países que recentemente se interessaram pela história dos livros escolares (especialmente Espanha, Itália, países da América Latina e da Europa Central e Oriental);

- as que consideram o livro como um objeto material e abordam as condições de produção, de autorização, de difusão, de financiamento e de utilização como produto escolar de maneira independente de seu conteúdo intelectual - esta tem sido a tendência majoritária de pesquisadores de países anglo-saxões, notadamente dos Estados Unidos (país precursor nesta temática), da Grã-Bretanha, ou, ainda, da Nova Zelândia;

- enfim, aqueles, atualmente ainda bastante minoritários, que se interessam pela recepção dos livros e a sua eficiência, isto é, quanto à ação que eles podem exercer (e as reações que podem suscitar) nos alunos e professores, mas também na opinião pública nacional, assim como na comunidade internacional.

No primeiro caso, a história produzida pelo pesquisador não é realmente a história dos livros: é a história de um tema, de uma noção, de uma disciplina, de uma personagem... tal como ela é apresentada pelo prisma da literatura escolar. Nas duas outras categorias, ao contrário, o historiador direciona sua atenção sobre o livro didático efetivamente, situando-os em seu contexto de produção, difusão, de seu uso ou sua recepção. Trata-se de uma concepção "ecológica" da literatura escolar, concepção esta que busca apreender o livro em seu contexto global e a recontextualizar o discurso por ele produzido.

A produção científica destes últimos trinta anos tem revelado várias tendências importantes:

- inicialmente houve um crescimento quantitativo considerável: em 1993, 45\% da produção francesa tinha menos de dez anos, e este número de pesquisas dobrou a partir desta data; neste mesmo ano de 1993, Circe Bittencourt defendeu sua tese, que foi o primeiro trabalho científico sobre a história do livro didático no Brasil, atualmente um dos países mais prolíferos neste tema. Constata-se igualmente um número crescente de países que não se preocupavam com tais questões, mas passaram a dedicar-se a eles: é o caso de muitos países da América Latina e da Europa Oriental e Central. De acordo com as tabelas que elaboramos, a produção científica mundial, com um crescimento anual de cem a duzentas referências novas apresentou, em dez anos, o dobro de pesquisas;

- ela se caracteriza também pelo surgimento e desenvolvimento de trabalhos que, embora permaneçam fiéis aos métodos clássicos de análise de conteúdos, têm feito investimentos em várias disciplinas, níveis de ensino, ou em setores de formação até então desprezados; têm introduzido temáticas novas, a maior parte das vezes relacionadas às preocupações contemporâneas; ou, ainda, têm considerado as dimensões iconográfica e tipográfica da literatura escolar, que eram anteriormente negligenciadas;

- também tem sido possível identificar aumento de trabalhos nos quais o livro é apreendido como produto cultural elaborado, fabricado, comercializado, consumido em um contexto específico: tem sido possivel, assim, criar uma série de sites que podem contribuir 
para a escrita, finalmente, de uma história globalizante da literatura escolar (história da regulamentação didática, da produção, das empresas editoriais, dos autores etc. );

- assiste-se, igualmente, a uma expansão do campo da pesquisa: têm sido analisados materiais periféricos, como cadernos de exercícios, murais, revistas pedagógicas, que tiveram um papel essencial na formação dos professores, documentos audiovisuais ou réguas de cálculo e materiais digitais; as coleções de documentos de bibliotecas, museus etc.;

- finalmente, as pesquisas começam a sair de uma visão tradicional centrada na problemática nacional: as questões sobre a utilização, tradução e adaptação de modelos estrangeiros tornaram-se objeto de numerosos estudos; e também as publicações importadas ou traduzidas destinadas à formação dos professores (obras e revistas pedagógicas), que comprovam a circulação de conteúdos de ensino e de métodos pedagógicos.

Todos estes avanços foram possíveis pela constituição de grandes instrumentos de pesquisa. Há cerca de quinze anos desenvolveram-se, em vários países, esforços importantes centrados em seis grandes projetos principais: o inventário de programas de ensino de diversas disciplinas; o levantamento de textos sobre a regulamentação política dos livros didáticos; o recenseamento da produção de livros escolares; o levantamento das revistas pedagógicas; o levantamento das empresas editorais; além do levantamento da produção científica.

0 levantamento de programas de ensino e de planos de estudos, incluindo aqueles destinados aos exames e testes, é, obviamente, um preâmbulo necessário a todo estudo das disciplinas pelos manuais, à medida em que eles se constituem por uma implementação mais ou menos fiel a tais documentos, na maioria dos países; as mudanças de programas incidem, evidentemente, sobre a produção escolar, que a transforma, ao menos teoricamente, em obras obsoletas.

0 recenseamento dos textos oficiais que regulamentam a concepção, a fabricação, a seleção, a difusão, o financiamento e a utilização dos livros didáticos é também fundamental. 0 conhecimento do contexto legislativo e de regulamentações dos livros escolares e sua evolução constituem-se, efetivamente, como preâmbulo indispensável de todo estudo sobre a história da edição escolar, uma vez que eles condicionam a existência, a estrutura e o processo de produção. 0 poder político define, por princípio, as regras do jogo para todos os atores da obra didática: primeiramente, para os que as concebem (autores e/ou editores), e, em seguida, para os professores que são obrigados a obedecê-las.

É ainda importante considerar que o recenseamento exaustivo da produção escolar articula-se a objetivos científicos, mas também a objetivos patrimoniais, e, neste aspecto, penso ser desnecessário destacar a importância desse abrangente inventário no mundo atual.

0 recenseamento dos periódicos pedagógicos, dentre outros interesses, é importante para debates sobre métodos de ensino: de uma certa forma, pode-se considerar as revistas como livros escolares para formação inicial de professores; elas contêm informações preciosas sobre as práticas nas salas de aulas.

Os aspectos econômicos, financeiros e de comercialização, assim como questões técnicas e materiais, foram aspectos que os pesquisadores negligenciaram por muito 
tempo, mas são tais pesquisas que têm permitido realizar o recenseamento das editoras e analisar suas estratégias e produções.

E, finalmente, o levantamento da produção científica, que corresponde ao cuidado em apresentar o estado da arte para evitar trabalhos redundantes e auxiliar as pesquisas bibliográficas, considerando-se que a pulverização das publicações, particularmente nesta área, tem dificultado esta atividade inicial da pesquisa.

Este esforço de capitalização e de difusão de recursos tem sido necessariamente realizado em uma esfera nacional, mas mesmo considerando que os avanços são, até o momento, diferenciados em cada país, tais pesquisas têm possibilitado alguns trabalhos comparativos.

Gostaria efetivamente de insistir sobre este aspecto, aparentemente paradoxal, sobre o caráter nacional - ou regional - da literatura escolar. Este caráter nacional é particularmente importante para a população e, mais ainda, tem sensibilizado também grupos locais e regionais. No entanto, esta reivindicação fundamental que se insere em questões de afırmação de uma identidade cultural mascara as influências e também intercâmbios culturais. Por intermédio da evangelização, da colonização ou da alfabetização em massa, alguns modelos nacionais foram, ou ainda são, exportados e difundidos em várias regiões. Os problemas relativos à utilização, à tradução, às adaptações de livros "exógenos", já têm sido objeto de um certo número de estudos, assim como existem trabalhos sobre publicações destinadas à formação de professores, geralmente de obras importadas, traduzidas ou inspiradas em modelos estrangeiros. Tem sido igualmente analisado o papel essencial de algumas congregações religiosas educacionais na difusão e adaptação, em muitos países, de edições que foram adaptadas às condições locais; existem também trabalhos cada vez mais numerosos dedicados à implantação e ao desenvolvimento de sucursais ou de filiais de editoras estrangeiras, especialmente na América Latina ou em territórios anteriormente administrados pelas grandes potências mundiais.

Afırmei no início desta fala que este colóquio se apresentou para mim como o momento da maturidade. Esta afirmação baseia-se em três elementos essenciais.

Em primeiro lugar, a importância atual da consulta pela internet. Paul Aubin e eu identificamos, em levantamento de 2006, cerca de cinquenta sites online: podem-se encontrar, evidentemente, sites especializados de bibliotecas de obras didáticas nacionais: Emmanuelle na França, Mascofo (Ontario) e Manscol (Quebec) no Canadá; Manes na Espanha e Red Patres Manes para América Latina, Bélgica e Portugal; Diaspora para publicações das comunidades de escolas cristãs; Edisco, na Itália e Livres, no Brasil (AUBIN; CHOPPIN, 2007). Mas se podem encontrar também pela internet catálogos de bibliotecas especializadas, de bibliografias de manuais, de bibliotecas digitais que colocam à disposição textos integrais, além de outros numerosos recursos constituídos por vários países.

0 segundo trabalho de pesquisa ao qual tenho me dedicado é sobre a constituição de um banco de dados para recensear o essencial da produção historiográfica mundial dos últimos cinquenta anos. Foram identificados, até o momento, aproximadamente 5.000 referências bibliográficas sobre a produção científica em aproximadamente quarenta países, e este levantamento está ainda em processo. Estes dados podem ser consultados, dentro de alguns meses, no site da minha instituição (INRP), por intermédio de um novo 
instrumento denominado Emma Internacional, que se constitui como um observatório internacional de pesquisa sobre o livro e edição escolares. Será possível efetuar várias pesquisas sobre o conjunto da produção científica sob múltiplos critérios relativos aos títulos, autores, disciplinas, níveis de ensino, períodos históricos, países pesquisados, ano da edição e temas abordados.

0 terceiro e último elemento é o projeto, bastante avançado atualmente, de constituição de um programa de consultas simultâneas pela internet de vários bancos de dados dedicados aos livros didáticos. Não continuarei a falar sobre este tema porque seguramente teremos ocasião de discutir bastante sobre esta questão no decorrer dos dias deste Colóquio.

Senhoras e senhores, caros colegas, caros amigos, o número de comunicações que será apresentado nestes quatro dias do Colóquio é um novo testemunho do dinamismo que caracteriza a pesquisa sobre o livro escolar e temos que nos congratular. É por intermédio de métodos, troca de informações, possibilidade de compartilhar experiências entre os pesquisadores ou de equipes de pesquisadores que trabalham com objetivos comuns e, evidentemente, pelo surgimento de uma comunidade científica, que a pesquisa progride. E não tenho dúvidas de que este colóquio irá contribuir muitíssimo para este progresso científico.

\section{Referências}

AUBIN, Paul; CHOPPIN, Alain. Le fonti storiche in rete: i manuali scolastici. In: GIANFRANCO BANDINI, Paolo Bianchini (dir.). Fare storia en rete: fonti e modelli di scrittura digitale per la storia dell'educazionnne, la storia moderna e la storia contemporânea. Firenze: Carocci, 2007. p. 53-57.

CHOPPIN, Alain. Contexte scientifique de la recherche sur l'édition scolaire au plan local, national et mondial. In: SIMPÓSIO INTERNACIONAL LIVRO DIDÁTICO: EDUCAÇÃO E HISTÓRIA, 2007, São Paulo. Atas do... São Paulo: USP, 2007. CD-ROM.

CHOPPIN, Alain. L'histoire des manuels scolaires: un bilan bibliométrique de la recherche française. In: CHOPPIN, Alain (org.). Manuels scolaires. Etats et sociétés XIX- XX siècles. Histoire de L'Education, n. 58 (spe.), p. 165-185, mai 1993.

CHOPPIN, Alain. Le manuel scolaire, une fausse evidence historique. Histoire de L'Education, n. 117, p. 7-56, 2008. Disponível em: http:histoire-education.revues.org/565. Acesso em: informar data

DANCE, Edward Herbert. History the Betrayer: a study in biais. London: Hutchinson, 1960. 162 p.

ECKERT, Georg. Internationale schulbuchrevision. Internationale Zeitschrift fur erziehungwissenschaft, v. 2, n. 6, p. 399-415, 1960. Ver se está correto v e n.

FRITSCHE, Karl-Peter. Schulbushforschung und schulbuchbeurteilung. In: FRITSCHE, Karl-Peter (org.). Schulbusher auf dem prufstand perspektiven der schulbushforschung und schulbushbeurteilung in Europa. Frankfurt: Diesterweg, 1992. p. 9-22. 
GORAN, Andolf. Historien på gymnasiet: undervisning och läroböcker 1820-1965. 1972. Diss. - Uppsala Universitet. Uppsala, 1972.

HARPER, G. H. Textbook: an under used source. History of Education Society Bulletin, v. 25, p. 30-40, 1980. JACOBMEYER, Wolfgang. International textbook research. Goteborg: Goteborg Universiteit, 1990. (Rapport; n. 2).

JEISMANN, Karl-Ernest. Internationale schulbuchforschung: aufgaben und probleme. Internationale Schulbuchforschung Zeitschrift des Georg-Eckert-Institut, v. 1, p. 7-22, 1979.

JEISMANN, Karll-Ernest. The construction of capitalism: modern British history as presented in East Germany's history textbook. In: BERGHAHN, Volker B.: HANNA, Schlisser (ed.). Perceptions of history: international textbook research in Britain, Germany and the United State. Oxford: Berg Publichers, 1987. p inicial e final.

JOHNSEN, Egil Borre. Textbook in the kaleidoscope: a critical survey of literature and research on educational texts. Oslo: Scandinavian University Press, 1993.

KUHN, Leo. Schulbuch, ein massmidium: informationen, gebrauchsanweisungen, alternativen. Wien: Munchen: Jugend und Volk, 1977.

LUNTINEM, Pertti. School history: textbooks revision by and under the auspices of Unesco. Internationale Schulbuchforschung Zeitschrift des Georg-Eckert-Institut, v. 10, n. 1, p. 39-48, 1989.

LUNTINEM, Pertti. School history: textbooks revision by and under the auspices of Unesco. Internationale Schulbuchforschung Zeitschrift des Georg-Eckert-Institut, v. 10, n. 4, p. 337-348, 1989.

MEHLINGER, Howard D. International textbook revision: examples from the United States. Internationale Schulbuchforschung Zeitschrift des Georg-Eckert-Institut, v. 7, n. 4. p. 287-298, 1985.

PRUDHOMMEAUX, Jules. Ênquete sur les livres scolaires d'après-guerre. Paris: Centre Européen de la Dotation Carnegie pour la Paix Internationale, 1926. 2. v. 1925-1927.

RIEMENSCHNEIDER, Rainer. Intentionem und perspcktiven internationaler schulbuchforschung. versuch einer bestandaufnahme. Internationale Schulbuchforschung Zeitschrift des Georg-Eckert-Institut, v. 3, n. 1, p. 5-15, 1981 .

SCHUDDEKOPF, Otto-Ernest. Zwanzig Jahre westeuropäischer schulgeschichtsbuchrevision: tatsachen und probleme: 1945-1965. Limbach: Brauwnscheig, 1966.

SCHALLENBERGER, Ernest-Horst. Aspekte und verfahren zur analyse. Ratingen: Kastellaun, 1973.

VIGANDER, Haakon. History teaching revisions. Strasbourg: Council for Cultural Co-operation of the Council of Europe, 1967. 
WEINBRENNER, Peter. Kategorien und methoden fur die analyse wirtschafts -und sozialwissenschaftlicher lehr-und lernmittel. Internationale Schulbuchforschung, Braunsweig, v. 8, n. 3, p. 321-337, 1986.

Alain Choppin (1948-2009). Formação pela Université de Paris I em Lettres Classiques e Doutor em História pela Université de Paris I - Pantheon-Sorbonne, em 1989; pesquisador do Service d'Histoire de l'Éducation do Institut National de Recherche Pédagogique (INRP) entre 1979 a 2009, criador do Programa de Pesquisa Emmanuelle e do banco de dados homônimo; um dos fundadores do IARTEM- The International Association for Research on Textbooks and Educational Media. 